\title{
The Roles of Motivation in Improving Productivity in Organizations
}

\author{
Li Yan \\ Management School, Massey University, New Zealand \\ Keywords: Motivation; Intrinsic; Extrinsic; Job Enrichment; Productivity \\ Abstract: Procuring high productivity is one of the most pivotal goals of an organization. \\ Motivation, an incentive factor that has the potential to enhance employee loyalty and \\ performance, can also contribute to increasing productivity when properly utilized by \\ managers. This paper presents current theories of motivation and outcomes of empirical \\ study to enunciate how employee motivation generates higher productivity in \\ organizations.
}

\section{Introduction}

Improving the productivity of the organization is one of the key tasks of managers. However, how to effectively increase organizational productivity is a highly controversial issue and can be regarded as a great challenge for managers. Theories of organizational behaviour play important roles in improving performance of the organization and some elements provide leaders with effective propositions to enhance organizational productivity. Motivation is a crucial factor contributing to the improvement of organizational productivity.

\section{The Role of Motivation in Improving Productivity}

\subsection{The Definition of Motivation and Various Motivation Theories}

Motivation is a foundational subject in psychology and organizational studies and it is significant to explain both individual and organizational behaviour. Motivations means "those psychological process that cause arousal, direction, and persistence of voluntary actions that are goal oriented (Mitchell, 1982: 81, cited by Ramlall, 2004: 53). Robbins (1993: 112), cited by Ramlall (2004: 53), defines motivation as "willingness to exert high levels of effort toward organizational goals, conditioned by the effort's ability to satisfy some individual need". Human motivation toward work can be divided into two types: intrinsic motivation and extrinsic motivation. Intrinsic motivation refers to people's desire to spend efforts due to the interest and enjoyment of the work itself (Ryan \& Deci, 2000). Extrinsic motivation means the desire to spend effort in order to obtain some outcomes that separated from the work itself such as reward or recognition (Amabile, 1993).

According to current theories, motivation emerges out of needs, goals, values, intensions and expectations (Valencia, 2005). These motivation theories mainly include need theories, equity theories, expectancy theories, goal setting theories and job design theories and models. 


\subsection{Theories of Motivation and Job Enrichment to Enhance Productivity}

Herzberg (1968) proposed the Motivator-Hygiene theory, which is one of the most influential theories of work motivation in recent decades. According to his theory, factors are divided into two categories: motivator factors, which are connected with the job itself, and hygiene factors, which are connected with the organizational context (Valencia, 2005). Motivator factors, including achievement, advancement, recognition, responsibility, personal growth and the work itself, can contribute to work satisfaction and motivate people towards a greater effort and performance (Huczynski \& Buchanan, 2007). Hygiene factors including working conditions, salary, security, company policies, status and interpersonal relationship can prevent dissatisfaction, but cannot motivate employees (Huczynski \& Buchanan, 2007). However, hygiene factors can demotivate employees if they are not sufficient. When the job is rich in motivator factors, employees will be most satisfied and productive. According to Herzberg's theory, in order to motivate employees and enhance the productivity, leaders need to do more than just providing compensation, good working conditions and other similar factors. He also suggests that in order to make an employee to be truly motivated, the job should be fully enriched to make sure that employees have access to achievement, recognition, responsibility and advancement (Ranlall, 2004). Job enrichment that aims at making the work itself interesting and challenging will lead to better performance and enhanced productivity of the organization. Therefore, leaders should emphasize and perform job enrichment, and the measures incorporate decreasing the level and frequency of control, providing employees with responsibility to check their own work and building a direct relationship between employees and customers (Herzberg, 1968; Khan, 1993).

Hackman and Oldham's job characteristics model, which involves job enrichment, suggests that employees will experience intrinsic motivation from the job itself when the job satisfies three important aspects of psychological needs (Pinder, 1984). Firstly, employees must feel they have the responsibility for the outcomes of the job. Secondly, the work must be recognized as meaningful by employees. Thirdly, employees must realize how effectiveness their efforts contribute to the performance of the organization. Consequently, the job should be designed to evoke employees' feeling of responsibility, meaningfulness and the knowledge of the results of their efforts (Ramlall, 2004). Hackman and Oldham (1976), cited by Valencia (2005), propose that to make the job itself more motivating, five components of motivation should be concerned: skill variety (the number of different skills needed by the job), task identity (the degree of meaningfulness of the work), task significance (the significance of the work), autonomy (the degree of self-control and freedom in how to perform their tasks), and feedback (the degree to which employees obtain the knowledge of the results).

The survey on Wallace Company (discussed in Khan, 1993: 150) showed that Wallace Company was a perfect example that adopted job enrichment to improve organizational performance and productivity. This company wined the prestigious Malcolm Baldrige National Quality Award in 1990. This company adopted a decentralized decision-making process that organizational units were empowered to act on their own. All the employees are called associates by the Wallace Company and they had the authority to make customer-related decisions up to $\$ 1000$ without higher permission. The employees working in the warehouse were given the authority to reject the shipment if the goods were defective or the shipment was incorrect. Wallace Company emphasized and invested a lot on employee training and education. Between 1987 and 1990, this company spent more than $\$ 2,000,000$ on formal education and job training of employees. The following statistics shows the productivity improvement of Wallace Company. Firstly, the total sales increased by $40 \%$ during the period 1985 to 1989 . Secondly, the sales rate of per-employee was $25 \%$ higher than that of the average high-performing companies in the industry. Thirdly, the profit-to-sales ratio increased 
by approximately $13 \%$.

Volvo Company also implemented job enrichment to increase productivity. In the late 1960s, Volvo Company started its job enrichment program involving about 1500 employees in Gothenburg (Gibson, 1973). This job enrichment program was a comprehensive program which incorporated new ideas in technology, work environment, work organization structure. This program brought about changes including new job structures, less control and supervision and more consultation with employees. The program provided employees with more training both at the beginning of hiring and subsequent periods, involving training in managerial ability, communication skills and leadership. It also gave the individuals and groups more authority on decision making. The surveys of employees of Volvo showed positive outcomes of performing this job enrichment program. The absenteeism rate and turnover of employees decreased and productivity greatly increased (Gibson, 1973).

\subsection{Expectancy Theory and Its Implication in Productivity Improvement}

Vroom's Expectancy theory states that motivation depends on individual's perceived probability that effort will lead to performance, the perceived value or preference of outcomes that will result from the performance, and the perceived probability that the outcomes will contribute to valued rewards (Huczynski \& Buchanan, 2007). If a person feels that he can do a work without any difficulty and the accomplishment of the job can contribute to valued rewards, he would be highly motivated to perform the work (Khan, 1993). To motivate employees in order to improve organizational productivity, leaders can establish a reward system with a clear connection between performance and reward.

Sonoco, a manufacturer of packaging for industrial and consumer goods, established a very clear connection between employee performance and reward based on the expectancy theory (Nohria et al, 2008). In 1995, under the new vice president of human resources, Sonoco established a pay-for-performance system based on individual and group performance. According to the outcomes of an administered internal survey, employee satisfaction and involvement improved and productivity increased (Nohria et al, 2008). In 2005, Hewitt Associates recognized Sonoco as one of the top 20 talent-management organizations in America.

Another example is that when the Royal Bank of Scotland acquired NatWest, the old reward system was operated based on politics, status and employee tenure. RBS adopted a new reward system that made managers responsible for clear and specific goals and rewarded employees who have good performance and effectively achieve their goals. The new reward system was embraced by employees and improved the organizational performance and productivity compared with the old reward system (Nohria et al, 2008).

\subsection{Goal Setting Theory and Its Role in Productivity Improvement}

The goal setting theory developed by Locke (1968) states that specific and challenging goals lead to higher performance than simple and vague goals. Employee's participation in goal setting and the knowledge of results of past performance (feedback) can lead to improved performance and effective goal achievement. The goal setting theory concerns the clarity of the practical management implications which include goal difficulty, goal specificity, employee participation and acceptance, and performance feedback (Lock \& Latham, 1990, cited by Huczynski \& Buchanan, 2007). To enhance productivity, when setting goals, leaders can follow the "principles of SMART, measurable, attainable, realistic and time-related" (Huczynski \& Buchanan, 2007: 255).

The high productivity of Wallace Company can also be explained in goal setting theory. The leaders of the company made very clear and specific goals such as improving quality on the guidelines of the Malcolm Baldrige award (Hill \& Freeman, 1992, cited by Khan, 1993). 
Employees were appropriately trained and supported, and highly motivated to achieve this goal.

\section{References}

[1] Amabile, T. M. (1993) Motivational Synergy: Towards New Conceptualization of Intrinsic and Extrinsic Motivation in the Workplace. Human Resource Management Review 3: 185-201.

[2] Gibson, C. H. (1973) Volvo Increases Productivity Through Job Enrichment. California Management Review 15 (4): 64-67.

[3] Herzberg, F. (1968) One More Time: How Do You Motivate Employees. Harvard Business Review 46 (1): 53 -62.

[4] Huczynski, A. \& Buchanan, D. (2007) Organizational Behaviour. London: Prentice Hall.

[5] Khan, M. S. (1993) Methods of Motivating for Increased Productivity. Journal of Management in Engineering 9 (2): 148-156.

[6] Locke, E. A. (1968) Toward a Theory of Task Motivation. Organizational Behaviour and Human Performance 3: 157-189.

[7] Nohria, N., Groysberg, B. \& Lee, L. E. (2008) Employee Motivation: A Powerful New Model. Harvard Business Review 86 (7/8): 78-84.

[8] Pinder, C. (1984) Work Motivation: Theory, Issues and Applications. Glenview: Scott, Foresman and Company.

[9] Ramlall, S. (2004) A Review of Employee Motivation Theories and Their Implications for Employee Retention within Organizations. Journal of American Academy of Business 5 (1/2): 52-61.

[10] Ryan, R. M. \& Deci, E. L. (2000) Self-Determination Theory and the Facilitation of Intrinsic Motivation, Social Development, and Well-being. American Psychologist 57: 749-761.

[11] Valencia, C. (2005) Motivation and Productivity in the Workplace. [online] Available from:http://www.westminstercollege.edu/myriad/index.cfm? parent $=2514 \&$ detail $=4475 \&$ content $=4798$ (accessed December 25th 2011) 